\title{
Neue Bücher
}

Erwin F r a u e n k n e c h t, Peter R ü c k e r t : Kaiser Karl IV. (1316-1378) und die Goldene Bulle. Begleitbuch und Katalog zur Ausstellung des Landesarchivs Baden-Württemberg, Hauptstaatsarchiv Stuttgart. Stuttgart (Kohlhammer) 2017. 154 S.

Zum 700. Geburtsjahr von Kaiser Karl IV. veranstaltete das Landesarchiv vom 13. April bis 29. Juli 2016 eine Ausstellung über diesen Kaiser und seine Goldene Bulle von 1356. Der hier zu besprechende Ausstellungskatalog enthält neben Bildern und Erklärungen zu den Exponaten auch sieben Aufsätze über Karl IV.

Der Aufsatzteil beginnt mit einem von Erwin Frauenknecht verfassten Überblick über Person, Dynastie und Herrschaft Karls IV. Zu Beginn werden die Verbindungen des jungen Karl IV. zu anderen Großen seiner Zeit beleuchtet, darunter Pierre Roger, der spätere Papst Clemens VI., der einer der Lehrer Karls IV. war. Die Biografie beleuchtet ebenso die Konflikte mit den böhmischen Adligen, den Weg vom Gegenkönig zum Kaiser und Karls Bautätigkeit in Prag. Abschließend wird die politische Herrschaft Karls IV. betrachtet, namentlich der Erbvertrag mit den Habsburgern, welcher 1437 zu deren Aufstieg zum Thron führte. Ebenso wird die Wahl von Karls Sohn Wenzel zum deutschen König 1376 beleuchtet, welche eigentlich den Bestimmungen der Goldenen Bulle widersprach.

Frauenknecht und Rückert gehen im nächsten Beitrag näher auf die Goldene Bulle ein, deren Regeln für die Königswahl bis zur Auflösung des Heiligen Römischen Reichs 1806 in Kraft waren. Auch die besondere Rolle Karls IV. wird betrachtet. Die weiteren Kapitel des Beitrags widmen sich Vorrechten, Rangfolge, Ämtern und Erbfolge der Kurfürsten sowie dem in der Bulle enthaltenen Konfliktpotenzial (Streit zwischen bayrischen und pfälzischen Wittelsbachern, Urkundenfälschungen Rudolfs IV. von Österreich und seines Schwiegersohns Karl IV.).

Claudia Garnier betrachtet dabei das Verhältnis von König und Kurfürsten, wie es durch die Goldene Bulle geregelt wurde, samt den Sonderaufgaben der Kurfürsten mit den Ritualen im Rahmen des Tafelzeremoniells.

Matthias Ohm erläutert im Kapitel „Groschen - Gulden - Heller“ die Münzpolitik Karls IV. inklusive dessen Einfluss auf die Münzprägung in Böhmen, den Kurfürstentümern am Rhein und in Württemberg.

Christian Jörg legt den Schwerpunkt in seinem Aufsatz auf Karl IV. und die Städtebünde in Schwaben. Dabei betrachtet er die Geschichte dieses Verhältnisses und die einschlägigen Bestimmungen der Goldenen Bulle. Die Entwicklung der Städtebünde in Schwaben und am Rhein bis zum Tod des Kaisers wird ausführlich erläutert.

Peter Rückert geht in seinem Aufsatz auf das Verhältnis zwischen Karl IV. und den Grafen von Württemberg ein. Er beginnt seine Ausführungen mit dem Ende der Stauferzeit und dem anschließenden Konflikt um das staufische Erbe. Gewisse thematische Überschneidungen mit den vorherigen Aufsätzen kommen vor.

Im letzten Aufsatz betrachtet Frauenknecht die Überlieferung und Rezeption der Goldenen Bulle. Er erläutert die Entstehungsgeschichte der sieben Ausfertigungen der Goldenen Bulle, welche für die Rezeption der Goldenen Bulle maßgeblich waren und erklärt die Entwicklung der Goldenen Bulle von einem Dokument, welches die Privilegien der Kurfürsten festhielt, zu einem Verfassungsdokument. Abschließend geht er noch auf das im Hauptstaatsarchiv Stuttgart liegende Exemplar der Goldenen Bulle ein, welches ursprünglich für den Trierer Erzbischof bestimmt war und 1803 in den Besitz des neu erhobenen Kurfürsten Friedrich von Württemberg kam. Im zweiten Teil des Buches werden die einzelnen Ausstellungsstücke näher beschrieben. Das Buch ist für alle interessant, die sich mit Karl IV. im Allgemeinen und Südwestdeutschland, darunter Württemberg im Besonderen, beschäftigen wollen.

André Baßler 